\title{
Impact of Food Preparation Video Exposure on Online Nutrition Education in Women, Infants, and Children (WIC) Program Participants: Retrospective Study
}

\author{
Robert J Bensley, PhD; John J Brusk, MPH

\section{Corresponding Author:} \\ Robert J Bensley, PhD \\ School of Interdisciplinary Health Programs \\ Western Michigan University \\ 2414 CHHS Building \\ 1903 W Michigan Avenue \\ Kalamazoo, MI, 49008 \\ United States \\ Phone: 12697162301 \\ Email: bensley@wmich.edu
}

School of Interdisciplinary Health Programs, Western Michigan University, Kalamazoo, MI, United States

\section{Abstract}

Background: The impact of integrating video into health education delivery has been extensively investigated; however, the effect of integrating video on a learner's subsequent performance in an online educational setting is rarely reported. Results of the relationship between the learner's online video viewing and subsequent progression toward health behavior change in a self-directed online educational session are lacking.

Objective: This study aimed to determine the relationship between viewing a Health eKitchen online video and key engagement performance indicators associated with online nutrition education for women, infants, and children (WIC).

Methods: This study involved a retrospective cohort of users grouped on the basis of whether Health eKitchen exposure occurred before or after completing a nutrition education lesson. A two-sample test for equality of proportions was performed to test the difference in the likelihood of progression between the groups overall and when stratified by lesson type, which was defined by whether the lesson focused on food preparation. Welch two-sample $t$ tests were performed to test the difference in average link depth and duration of use between groups overall and stratified by lesson type. Logistic regression was conducted to validate the impact of video viewing prior to lesson completion while controlling for lesson type and factors known to be associated with WIC key performance indicators.

Results: A greater stage of change progression was observed for both food preparation $\left(\chi^{2}=12.6, P<.001\right)$ and non-food preparation $\left(\chi^{2}=62.8, P<.001\right)$ lessons among early stage users who had viewed a Health eKitchen video before completing a lesson. Time spent viewing educational learning resource links within the lesson was also significantly longer for both food preparation $(t=7.8, P<.001)$ and non-food preparation $(t=2.5, P=.01)$ lessons. Logistic regression analysis corroborated these results while controlling for known confounding factors. The odds of user progression were nearly three times greater among those who viewed a Health eKitchen video prior to lesson completion (odds ratio=2.61; 95\% CI=2.08-3.29). Type of lesson (food vs non-food preparation) was the strongest predictor of progression odds (odds ratio=3.12; 95\% CI=2.47-3.95).

Conclusions: User access to a Health eKitchen video prior to completion of an online educational session had a significant impact on achieving lesson goals, regardless of the food preparation focus. This observation suggests the potential benefit of providing an application-oriented video at the onset of online nutrition education lessons.

(JMIR Formativ Res 2019;3(1):e12508) doi: 10.2196/12508

\section{KEYWORDS}

internet; online video; WIC; engagement 


\section{Introduction}

The federally funded Special Supplemental Nutrition Program for Women, Infants, and Children (WIC) provides qualified program participants who are at nutrition risk due to insufficient financial access to nutritious foods to supplement diets, information on healthy eating, and referrals to health care. Many positive health outcomes have been associated with the program, including improved diet, infant feeding practices, and preconceptual nutrition status [1]. Wichealth.org [2] is an online educational framework in which clients engage to meet the educational requirements in order to be eligible for the WIC program. People who complete wichealth.org lessons demonstrate very high rates of positive movement with belief in their ability to engage in various health-promoting nutritional and physical activity behaviors $[3,4]$. Over the last decade, many enhancements have been made to wichealth.org to provide continuous improvement with respect to various key performance indicators. These enhancements indicate the value of education for the client, including both engagement extent and duration, as well as the subsequent impact to the client's current readiness to change behavior. One of these enhancements was the Health eKitchen curated library of existing internet-based food preparation and cooking videos available to users of wichealth.org. Videos consist of short segments (eg, 2-3 minutes in length) that demonstrate how to prepare and cook recipes using specific foods associated with the WIC food package. A recent review of Health eKitchen usage patterns suggested a positive relationship between video access and wichealth.org user lesson progression.

The impact of integrating video into health education delivery has been extensively investigated to determine whether learning objectives can be achieved more effectively and with greater learner satisfaction than interventions that do not use any technology [5-10]. This is also true for other educational disciplines that do not focus on health [11-14]. Typical investigations concerning the use of video, whether integrated into a face-to-face or online educational setting or not, aim at comparing the use of one or more modalities on the learning outcome of interest [15-17]. However, the effect of integrating video on a learner's subsequent performance in an online educational setting is scarcely reported [18]. Further, to our knowledge, no study has specifically reported on the relationship between learner online video viewing and the learner's subsequent progression toward health behavior change in a self-directed online educational session. Studies that focused on the effect of video use within the context of an online educational setting tended to focus on user satisfaction and knowledge recall, where online learner satisfaction has been demonstrated to be strongly associated with learner engagement in the educational content [19-21]. Furthermore, inclusion of videos can increase learner motivation to learn and subsequent engagement with online course content [16].

Typical studies concerning the impact of video use in an online learning environment focus on comparing various educational modalities that include video with those that do not or those that have varying levels of interactive video integrated $[14,16,22]$. Choi and Johnson conducted similar work, wherein various online learning environments that included or did not include the use of video instruction were compared [23]. Most reports identified a significant improvement in learners' motivation when online videos were integrated. Increase in online learner engagement through the use of videos has also been demonstrated physiologically: Using electrodermal activity and heart rate measurements, van Bruinessen and colleagues showed that a moderate level of increased arousal is ideal to increase learning capacity in an online self-help intervention [18].

The purpose of this study was to determine the relationship between viewing of a Health eKitchen online video and key engagement performance indicators associated with WIC online nutrition education.

\section{Methods}

\section{Participants}

The sample used for this study was derived from WIC clients across 21 US states, who completed a wichealth.org lesson during a 34-month period in the government's 2014-2016 fiscal years. Participating subjects chose to complete a wichealth.org lesson as a means of meeting secondary contact requirements associated with the WIC program. Data-collection protocols using wichealth.org were approved for use by the Western Michigan University's Human Subjects Institutional Review Board. Online informed consent was provided prior to completion of the online survey.

\section{Data Collection}

Data utilized in this study were collected from 4460 wichealth.org uses from the system database for WIC clients who started an English-based lesson in one of the first three stages of the Transtheoretical Model (ie, precontemplation, contemplation, and preparation), completed the lesson, and viewed at least one Health eKitchen video during their session. Only the individuals who began a lesson in the early stages of readiness to change, not those in the active change stages, could have measurable progression at the time of lesson completion.

All lessons were completed using the wichealth.org website application. Data consisted of six system-collected measures (links viewed, link view time, device type, beginning stage of change, ending stage of change, and lessons completed), four profile items (ethnicity, race, pregnancy status, and age), and time at which the Health eKitchen video was viewed. The staging algorithms used to identify the beginning and ending stages were based on criteria previously used to determine stages of change and progression, which have been described in detail elsewhere $[3,4]$.

\section{Statistical Analysis}

Binary progression-irrespective of whether a subject advanced in stage of change intent-was the dependent variable used. The primary independent variable of interest was subject exposure to a Health eKitchen video prior to completion of a wichealth.org lesson. Over the past decade, program evaluations conducted every 6 months demonstrated the importance of other variables currently collected from users of wichealth.org. These 
include user demographic characteristics of race, ethnicity, pregnancy status, and age as well as system access characteristics including device type (fixed, such as a desktop or laptop, vs mobile), lesson type (feeding behavior focus vs other), number of internet resource links accessed (depth), and duration of all resource links used. Each of these variables was considered a possible effect modifier or confounder of the relationship of interest. Depth and duration of link use are key performance indicators for wichealth.org previously demonstrated to be strongly associated with users' stage of change progression [24]. Lesson type was also assigned based on whether the wichealth.org lesson content focused on feeding behaviors that would be relevant to Health eKitchen videos about food preparation and recipes. Lesson type was included in the model to determine whether the impact of a video view on a lesson is associated with whether the lesson addresses content related to food preparation and recipes.

In order to control for motivation bias potentially confounding the positive relationship between lesson engagement and viewing a Health eKitchen video prior to wichealth.org lesson completion, users who chose to view a Health eKitchen video after completing a wichealth.org lesson were used as the comparison group. Similar to users who viewed a Health eKitchen video prior to their lesson, these individuals were motivated to view a video, but they viewed the video after their lesson. As users access Health eKitchen by their own choice and motivation, it is likely they are motivated to be engaged to a greater extent and subsequently more likely to progress in the stage of readiness change compared to users that opt not to access Health eKitchen at all.

A two-sample test for equality of proportions was performed to test the difference in the likelihood of progression between comparison groups. Likewise, this difference was tested for each of the covariates: Welch two-sample $t$ tests were performed to test whether link depth and duration were associated with user progression and each of the covariates. The Welch $t$ test adjusts the number of degrees of freedom when the variances are not equal between groups. A logistic regression was conducted to evaluate the odds of progression for users who viewed a Health eKitchen video prior to subsequent completion of a wichealth.org lesson compared to those who did not. All data were analyzed using the $\mathrm{R}$ statistical package [25].

\section{Results}

Approximately half $(2301 / 4460,51.59 \%)$ of the subjects included in this investigation reported that they were of Latino ethnicity, and $58.5 \%$ of subjects belonged to a race other than white. Most (4206/4460, 94.30\%) subjects were mothers of the child who was receiving WIC benefits. In addition, 2655 of the subjects $(59.53 \%)$ completed the lessons using a fixed device. As expected, device type and lesson type were both significantly associated with the outcome of interest or at least one of the wichealth.org key performance indicators $(P<.001$; Table 1$)$. Further, age group was associated with the outcome of interest and both wichealth.org key performance indicators presented. None of the other demographic variables were significantly associated with progression, link use depth, or link use duration (Table 1).

The wichealth.org stage of change progression (one or more stages) was significantly associated with whether a user accessed a Health eKitchen video prior to their lesson $\left(\chi^{2}=127.2, P<.001\right.$; Table 2). Further, the average time spent by users on links during the lesson was significantly more for users who viewed a Health eKitchen video prior to the lesson $(t=8.2, P<.001)$. In addition, both food preparation $\left(\chi^{2}=12.6, P<.001\right)$ and non-food preparation $\left(\chi^{2}=62.8, P<.001\right)$ lessons demonstrated significantly greater progression among early stage of change subjects who viewed a Health eKitchen video prior to the lesson. Similarly, the average time spent was significantly longer for both food preparation $(t=7.8, P<.001)$ and non-food preparation $(t=2.5$, $P=.01)$ lessons among users who viewed a Health eKitchen video prior to the lesson.

Only predictors significantly associated with the odds of stage progression were included in the model (Table 3). Although age group was associated with the outcome of interest, it was not a significant contributor to the model and was therefore not included. Viewing of a Health eKitchen video prior to completion of a lesson was associated with nearly three times the odds of progression as that for subjects who did not view a Health eKitchen video until after lesson completion (odds ratio=2.61; 95\% $\mathrm{CI}=2.08-3.29$ ). Lesson type was the strongest predictor of progression odds (odds ratio $=3.12$; 95\% $\mathrm{CI}=2.47-3.95$ ). 
Table 1. Characteristics of early beginning-stage users who accessed Health eKitchen.

\begin{tabular}{|c|c|c|c|c|}
\hline Demographic & Early state users $(\mathrm{N}=4460)$ & $\begin{array}{l}\% \text { Progression in stage of } \\
\text { change }\end{array}$ & Average link views & Average link minutes \\
\hline \multicolumn{5}{|l|}{ Device type } \\
\hline Fixed & 2655 & 91.1 & $2.8^{\mathrm{a}}$ & $5.7^{\mathrm{a}}$ \\
\hline Mobile & 1805 & 91.3 & 1.1 & 1.7 \\
\hline \multicolumn{5}{|l|}{ Lesson type } \\
\hline Non-food preparation & 1557 & 81.5 & 1.9 & 3.2 \\
\hline Food preparation & 2903 & $96.3^{\mathrm{a}}$ & 2.2 & $4.6^{\mathrm{a}}$ \\
\hline \multicolumn{5}{|l|}{ Race } \\
\hline White & 1853 & 91.3 & 2.2 & 4.0 \\
\hline Non-white & 2607 & 91.1 & 2.1 & 4.1 \\
\hline \multicolumn{5}{|l|}{ Latino ethnicity } \\
\hline No & 2159 & 89.7 & 2.2 & 4.0 \\
\hline Yes & 2301 & 92.5 & 2.0 & 4.1 \\
\hline \multicolumn{5}{|l|}{ Pregnancy status } \\
\hline No & 3694 & 91.4 & 2.1 & 4.1 \\
\hline Yes & 767 & 89.8 & 2.2 & 4.1 \\
\hline \multicolumn{5}{|l|}{ User age group } \\
\hline$<31$ years & 2404 & 90.1 & 2.0 & 3.5 \\
\hline$\geq 31$ years & 1972 & $92.5^{\mathrm{a}}$ & $2.3^{\mathrm{a}}$ & $4.8^{\mathrm{a}}$ \\
\hline
\end{tabular}

${ }^{\mathrm{a}} P<.001$.

Table 2. Key performance indicators according to Health eKitchen video viewing.

\begin{tabular}{|c|c|c|c|c|}
\hline $\begin{array}{l}\text { Health eKitchen video viewed } \\
\text { prior to lesson }\end{array}$ & Early state users $(\mathrm{N}=4460)$ & $\begin{array}{l}\% \text { Progression in stage of } \\
\text { change }\end{array}$ & Average link views & Average link minutes \\
\hline \multicolumn{5}{|l|}{ Overall } \\
\hline No & 913 & 81.7 & 2.08 & 2.69 \\
\hline Yes & 3547 & $93.6^{\mathrm{a}}$ & 2.14 & $4.45^{\mathrm{a}}$ \\
\hline Non-food preparation & 1557 & 81.5 & 1.9 & 3.2 \\
\hline No & 470 & 71.7 & 1.9 & 2.5 \\
\hline Yes & 1087 & $85.7^{\mathrm{a}}$ & 1.9 & $3.5^{\mathrm{b}}$ \\
\hline Food preparation & 2903 & 96.3 & 2.2 & 4.6 \\
\hline No & 443 & 92.3 & 2.3 & 2.9 \\
\hline Yes & 2460 & $97.1^{\mathrm{a}}$ & 2.2 & $4.9^{\mathrm{a}}$ \\
\hline
\end{tabular}

${ }^{\mathrm{a}} P<.001$.

${ }^{\mathrm{b}} P=.01$. 
Table 3. Results of independent samples study group logistic regression model.

\begin{tabular}{lllllll}
\hline Predictor of model feature & Estimate $B$ & SE $B$ & $z$ & Pr $(>|z|)$ & Odds ratio & $95 \%$ CI \\
\hline Intercept & 0.39 & 0.12 & 3.24 & $0.00121^{\mathrm{a}}$ & 1.47 & $2.17-1.87$ \\
Health eKitchen view prior to the lesson & 0.96 & 0.12 & 8.22 & $0.00000^{\mathrm{b}}$ & 2.61 & $3.08-3.29$ \\
Lesson type & 1.14 & 0.12 & 9.53 & $0.00000^{\mathrm{b}}$ & 3.12 & $1.47-3.95$ \\
Device type & 0.49 & 0.12 & 4.07 & $0.00005^{\mathrm{b}}$ & 1.63 & $1.29-2.07$ \\
Link views & 0.28 & 0.04 & 6.30 & $0.00000^{\mathrm{b}}$ & 1.32 & $1.22-1.43$ \\
Link minutes & 0.05 & 0.02 & 2.59 & $0.00967^{\mathrm{a}}$ & 1.05 & $1.01-1.09$ \\
\hline
\end{tabular}

${ }^{\mathrm{a}} P<.01$.

${ }^{\mathrm{b}} P<.001$.

\section{Discussion}

\section{Principal Findings}

Video use has been well demonstrated as a valuable and impactful tool in the online educational setting. This study evaluated the effect of video viewing on intent to change parent-child feeding behavior when the video was viewed before beginning the educational lesson. Potential for confounding caused by motivation or volunteer bias associated with learners who chose to view a Health eKitchen video prior to their lesson was minimized, as the comparison group also chose to view Health eKitchen videos but did so after completion of their educational session.

The results of this study are important, because even though online nutrition education programs have been found to have an impact on various aspects associated with nutrition behaviors among WIC clients, including belief in ability and intent to positively impact parent-child feeding, knowledge and behaviors surrounding eating breakfast, and reduction in salt intake [3-5,26,27], the specific effect of video viewing on achieving online educational objectives when viewed by learners before engaging in a lesson of interest is not well reported in the literature, especially in the WIC setting. To our knowledge, only one published study deemed the use of a training video on how to access a WIC online nutrition education program as helpful in reducing challenges with online access [5]. However, examining the usefulness of instructional video on tasks associated with logging in and negotiating a website is very different from determining the relationship between video viewing and key performance indicator engagement, which was the basis of the current study.

Findings from this investigation suggest that early stage wichealth.org users were more successful in progressing in stage of behavior change intent when the session focusing on that behavior was preceded by a Health eKitchen video view as compared to when it was followed by video viewing while controlling for other key predictors of progression. It was expected that if an effect was identified, it would be limited to lessons focusing on meal-preparation behaviors, as Health eKitchen videos would mostly be relevant to such behaviors, rather than lessons focusing on, for example, behaviors such as physical activity or dental hygiene. However, users of non-meal preparation lessons benefited to a similar extent as users of meal preparation lessons when they used Health eKitchen before completing their lesson, suggesting that the content of the video may be less important than the arousal or level of engagement that may be incited in the learner following video viewing. A previous study on the use of video and its ability to enable deep learning that touched on the subject reported that the relevance of the video with a learning objective should be carefully considered and clear to the user [28]. In contrast, the current study indicated that the use of video may have a positive impact regardless of whether it is specifically related to a behavior change focus. Here, the degree of relevance may be important. In addition, the fact that the Health eKitchen videos are related to personal health choices may be relevant enough to stimulate the user's motivation and interest in learning more about different, yet related, topics.

\section{Limitations}

Subjects chose whether they wanted to use wichealth.org as the method for completing secondary contact requirements, which limits the ability to generalize the results of this study to the entire WIC population. In addition, Health eKitchen is a separate feature that does not qualify for secondary contact credit. As such, the two groups compared in this study may differ in how they approach educational learning. Nonetheless, the use of video prior to initiating an online learning session appears to be an important strategy to employ in e-learning environment designs in order to maximize user engagement and subsequent achievement of learning objectives.

\section{Recommendations}

We recommend that a more rigorous study be conducted to confirm our findings and allow generalization of the results to a broad audience of WIC participants. Additional studies could focus on introducing video learning in other online education and behavior change programs used by WIC to determine if our findings are applicable to any online learning approach with WIC clients or specific to the Health eKitchen feature available within the wichealth.org nutrition education platform. The use of video prior to the use of other traditional educational formats available within WIC clinics, such as information malls and one-on-one nutrition counseling, could be explored as a means for potentially impacting client engagement. Many clinics provide kiosks or looping videos in clinic waiting areas where 
nutrition-related videos could be shown. Although not the same as an online format, the implication that the use of video may, to some degree, influence client engagement warrants exploration of this method of learning.

\section{Conclusions}

This study is useful to nutritionists and WIC staff for developing or adopting online nutrition education and behavior change interventions, especially for WIC populations. This study showed that viewing a video prior to lesson completion was positively related to subject engagement in the online educational session.

\section{Acknowledgments}

JJB conducted data analysis. RJB secured funding for data collection and is the Director of wichealth.org. Both authors drafted the manuscript. Funding from wichealth.org USDA state partners provided the ability to deliver wichealth.org to WIC clients, resulting in the availability of data for analysis in this study.

\section{Conflicts of Interest}

None declared.

\section{References}

1. United States Department of Agriculture - Food and Nutrition Service. 2013. Women, Infants and Children (WIC): About WIC - How WIC Helps URL: https://www.fns.usda.gov/wic/about-wic-how-wic-helps [accessed 2018-12-26] [WebCite Cache ID 6kAngQGL2]

2. Wichealth. URL: https://wichealth.org/ [accessed 2019-01-15] [WebCite Cache ID 75RkUxGOV]

3. Bensley RJ, Brusk JJ, Anderson JV, Mercer N, Rivas J, Broadbent LN. wichealth.org: impact of a stages of change-based Internet nutrition education program. J Nutr Educ Behav 2006;38(4):222-229. [doi: 10.1016/j.jneb.2006.03.008] [Medline: 16785091]

4. Bensley RJ, Anderson JV, Brusk JJ, Mercer N, Rivas J. Impact of internet vs traditional Special Supplemental Nutrition Program for Women, Infants, and Children nutrition education on fruit and vegetable intake. J Am Diet Assoc 2011 May;111(5):749-755. [doi: 10.1016/j.jada.2011.02.010] [Medline: 21515124]

5. Au LE, Whaley S, Gurzo K, Meza M, Ritchie LD. If You Build It They Will Come: Satisfaction of WIC Participants With Online and Traditional In-Person Nutrition Education. J Nutr Educ Behav 2016 Dec;48(5):336-342.e1. [doi: 10.1016/j.jneb.2016.02.011] [Medline: 27017051]

6. Armstrong AW, Idriss NZ, Kim RH. Effects of video-based, online education on behavioral and knowledge outcomes in sunscreen use: a randomized controlled trial. Patient Educ Couns 2011 May;83(2):273-277. [doi: 10.1016/j.pec.2010.04.033] [Medline: 20570081]

7. Atack L, Luke R. Impact of an online course on infection control and prevention competencies. J Adv Nurs 2008 Jul;63(2):175-180. [doi: 10.1111/j.1365-2648.2008.04660.x] [Medline: 18638159]

8. Goodman K, Nowacki A, Wu J, Hickner J. Utilization and impact of pre-office visit video health maintenance education. Patient Educ Couns 2011 Nov;85(2):e65-e68. [doi: 10.1016/j.pec.2011.02.012] [Medline: 21414738]

9. Hsin WJ, Cigas J. Short videos improve student learning in online education. Journal of Computing Sciences in College 2013 May 2013 May;28(5):253-259.

10. Prober CG, Khan S. Medical education reimagined: a call to action. Acad Med 2013 Oct;88(10):1407-1410. [doi: 10.1097/ACM.0b013e3182a368bd] [Medline: 23969367]

11. Devaney TA. Impact of video tutorials in an online educational statistics course. J Online Learn Teach 2009;5(4):600.

12. Dupuis J, Coutu J, Laneuville O. Application of linear mixed-effect models for the analysis of exam scores: Online video associated with higher scores for undergraduate students with lower grades. Computers \& Education 2013 Aug;66:64-73. [doi: 10.1016/j.compedu.2013.02.011]

13. Torres-Ramírez M, García-Domingo B, Aguilera J, de la Casa J. Video-sharing educational tool applied to the teaching in renewable energy subjects. Computers \& Education 2014 Apr;73:160-177. [doi: 10.1016/j.compedu.2013.12.014]

14. Zhang D, Zhou L, Briggs RO, Nunamaker JF. Instructional video in e-learning: Assessing the impact of interactive video on learning effectiveness. Information \& Management 2006 Jan;43(1):15-27. [doi: 10.1016/j.im.2005.01.004]

15. Bol N, Smets EM, Rutgers MM, Burgers JA, de Haes HC, Loos EF, et al. Do videos improve website satisfaction and recall of online cancer-related information in older lung cancer patients? Patient Educ Couns 2013 Sep;92(3):404-412. [doi: 10.1016/j.pec.2013.06.004] [Medline: 23820196]

16. Guo PJ, Kim J, Rubin R. How video production affects student engagement: an empirical study of MOOC videos. In: Proceedings of the first ACM Conference on Learning @ Scale. New York: ACM; 2014:41-50.

17. Havice PA, Davis TT, Foxx KW, Havice WL. The impact of rich media presentations on a distributed learning environmentngagement and satisfaction of undergraduate students. Quarterly Review of Distance Education 2010;11(1):53-58. 
18. van Bruinessen IR, van den Ende IT, Visser LN, van Dulmen S. The impact of watching educational video clips on analogue patients' physiological arousal and information recall. Patient Educ Couns 2016 Feb;99(2):243-249. [doi: 10.1016/j.pec.2015.08.022] [Medline: 26427309]

19. Chejlyk S. The effects of online course format and three components of student perceived interactions on overall course satisfaction. Diss Abstr Int 2006;67(04) (UMI No. 3213421).

20. Keeler LC. Student satisfaction and types of interaction in distance education courses. Diss Abstr Int 2006;67(09) (UMI No. 3233345).

21. Kuo YC, Walker AE, Belland BR, Schroder KEE. A predictive study of student satisfaction in online education programs. International Review of Research in Open and Distributed Learning 2013 Mar;4(1):16-39.

22. Vural OF. The impact of a question-embedded video-based learning tool on e-learning. Educational Sciences: Theory and Practice 2013;13(2):1315-1323.

23. Choi HJ, Johnson SD. The Effect of Context-Based Video Instruction on Learning and Motivation in Online Courses. American Journal of Distance Education 2005 Dec;19(4):215-227. [doi: 10.1207/s15389286ajde1904_3]

24. Brusk JJ, Bensley RJ. A Comparison of Mobile and Fixed Device Access on User Engagement Associated With Women, Infants, and Children (WIC) Online Nutrition Education. JMIR Res Protoc 2016 Nov 15;5(4):e216 [FREE Full text] [doi: 10.2196/resprot.6608] [Medline: 27847351]

25. R Core Team. R: A language and environment for statistical computing. Vienna, Austria: R Foundation for Statistical Computing URL: http://www.r-project.org/ [accessed 2019-01-15] [WebCite Cache ID 75RlOCViA]

26. Au LE, Whaley S, Gurzo K, Meza M, Rosen NJ, Ritchie LD. Evaluation of Online and In-Person Nutrition Education Related to Salt Knowledge and Behaviors among Special Supplemental Nutrition Program for Women, Infants, and Children Participants. J Acad Nutr Diet 2017 Sep;117(9):1384-1395. [doi: 10.1016/j.jand.2016.12.013] [Medline: 28196620]

27. Au LE, Whaley S, Rosen NJ, Meza M, Ritchie LD. Online and In-Person Nutrition Education Improves Breakfast Knowledge, Attitudes, and Behaviors: A Randomized Trial of Participants in the Special Supplemental Nutrition Program for Women, Infants, and Children. J Acad Nutr Diet 2016 Mar;116(3):490-500. [doi: 10.1016/j.jand.2015.10.012] [Medline: 26669795]

28. Mitra B, Lewin - Jones J, Barrett H, Williamson S. The use of video to enable deep learning. Research in Post-Compulsory Education 2010 Dec;15(4):405-414. [doi: 10.1080/13596748.2010.526802]

\section{Abbreviations \\ WIC: Women, Infants, and Children}

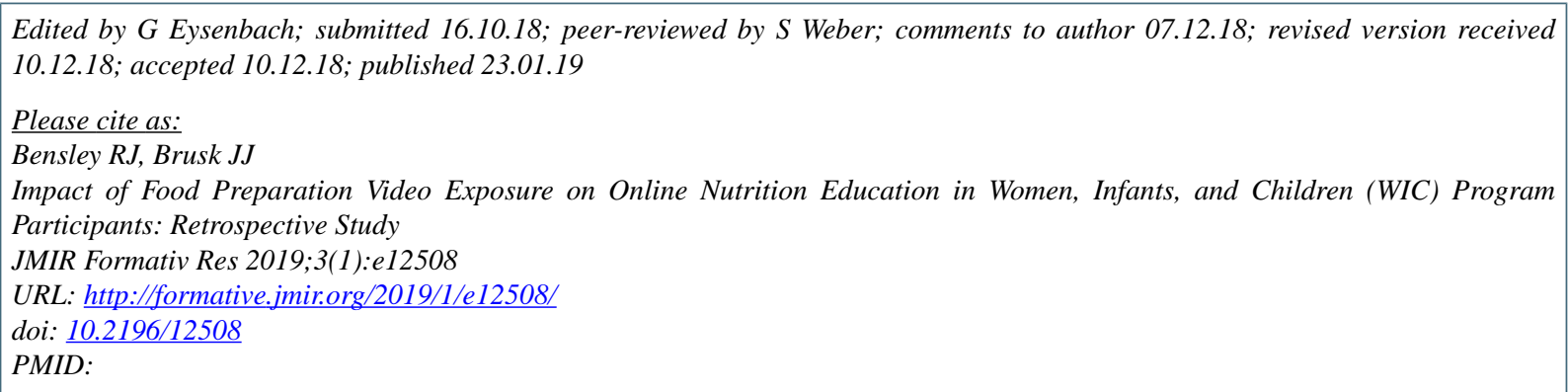

CRobert J Bensley, John J Brusk. Originally published in JMIR Formative Research (http://formative.jmir.org), 23.01.2019. This is an open-access article distributed under the terms of the Creative Commons Attribution License (https://creativecommons.org/licenses/by/4.0/), which permits unrestricted use, distribution, and reproduction in any medium, provided the original work, first published in JMIR Formative Research, is properly cited. The complete bibliographic information, a link to the original publication on http://formative.jmir.org, as well as this copyright and license information must be included. 